\title{
Contextual influences on the role of evidence in health policy development: insights from India and Nigeria
}

\author{
Tolib Mirzoev*, Mahua Das, Bassey Ebenso ${ }^{1}$, Bindiya Rawat ${ }^{2}$, Nkoli Uguru $^{3}$, Giuliano Russo ${ }^{4}$, Roger Bymolt ${ }^{5}$, \\ Reinhard Huss ${ }^{1}$
}

From Health Services Research: Evidence-based practice

London, UK. 1-3 July 2014

\section{Background}

The context is a complex and important influence on decision-making, affecting degree of responsiveness and people-centred health systems. Although theoretical frameworks to understand context are available, limited empirical research exists exploring contextual influences on evidence-informed health policymaking. This presentation compares contextual influences on the role of evidence in health policy development within two large countries within their continents: India and Nigeria.

\section{Materials and methods}

In each country, the contextual influences on the development of three specific health policies were explored. The study was guided by a conceptual framework, developed from the literature. Context includes factors at three levels: macro (e.g. political and resource environment), meso (e.g. organisation's roles and practices) and micro (e.g. individual values and preferences). Data was collected using 72 in-depth interviews with key policy actors and document reviews, and analysed using framework approach.

\section{Results}

All policies were perceived as evidence-informed. Both formal (e.g. research) and informal (e.g. experiences) evidence was used in India; in Nigeria reliance was mostly on formal evidence. Key macro-level facilitators of evidence-informed decisions were international treaties driving reform agendas, leadership changes and political will. Key constraints included limited resources and opposition from powerful actors. At meso-level, civil society was particularly influential in India; whereas international agencies had greater role in policy decisions, including evidence use, in Nigeria. At micro-level, individuals had different understandings of what constitutes 'robust' evidence for policymaking, shaping their evidence preferences and decision-making practices.

\section{Conclusions}

Understanding context is essential in ensuring responsiveness of policy decisions to the needs of key policy actors within people-centred systems, for example through recognising actors' agendas and interests. Powerful civil society can catalyse greater recognition of citizens voice through communicating informal evidence, as we found in India; and influential donors can favour costly surveys, thus undermining use of evidence from government health information systems, as in Nigeria.

\section{Authors' details}

'University of Leeds, Leeds, UK. ${ }^{2}$ Association for Stimulating Know How, New Delhi, India. ${ }^{3}$ College of Medicine, University of Nigeria Enugu Campus, Enugu, Nigeria. ${ }^{4}$ Instituto de Higiene e Medicina Tropical, Lisbon, Portugal. ${ }^{5}$ Royal Tropical Institute, Amsterdam, The Netherlands.

Published: 7 July 2014

\section{doi:10.1186/1472-6963-14-S2-05}

Cite this article as: Mirzoev et al: Contextual influences on the role of evidence in health policy development: insights from India and Nigeria. BMC Health Services Research 2014 14(Suppl 2):O5.

'University of Leeds, Leeds, UK

Full list of author information is available at the end of the article 